\title{
How Students' Multiple Intelligences Differ in Terms of College and Gender
}

\author{
Ra'ed Abdelkarim \\ College of Arts and Applied Science \\ Mathematics and Sciences Unit \\ Dhofar University \\ Salalah, Oman \\ Khedr Abo Hassan \\ Reem Abuiyada \\ College of Arts and Applied Sciences \\ Dhofar University, Salalah \\ Oman
}

\begin{abstract}
This study explores multiple intelligences profiles among students at Dhofar University and investigates the differences in students' multiple intelligences according to college variable (College of Arts and Applied Sciences (CAAS), College of Commerce and Business Administration (CCBA), College of Engineering (CE), and College of Law $(C L))$ and gender variable. A scale of Multiple Intelligences developed by the researchers was applied on (320) students. Mean, standard deviation and MANOVA test were used for statistical analysis. The results of the study show that males and females rank their self-first in intrapersonal intelligences and last in musical intelligences. The results also show that there are statistically significant differences only in Spatial intelligence and Intrapersonal intelligence in favor of females for both intelligences. Regarding college variable, the study finds that there are statistically significant differences in four intelligences: Spatial, Kinesthetic, Musical, and Naturalist intelligences. The MANOVA test highlights the superiority of Engineering students in the four intelligence.
\end{abstract}

Keywords: Multiple Intelligences, Gender, College, Higher Education

Educators and Psychologists considered intelligence an important factor in their researches. The definition of intelligence has always been a controversial issue. Some scientist claimed that intelligence is related to neurological efficiency (Sternberg, 1990). According to Vygotsky, the individual's development is a result of his or her culture. Vygotsky felt social learning precedes development. He states: "Every function in the child's cultural development appears twice: first, on the social level, and later, on the individual level; first, between people (interpsychological) and then inside the child (intrapsychological)", (Vygotsky,1978).

"Intelligence is the aggregate or global capacity of the individual to act purposefully, to think rationally and to deal effectively with his environment (Wechsler, 1944)." which means that the term intelligence is not a single ability.

In 1983, Gardner published his theory: Frames of Mind: The Theory of Multiple Intelligences. The revolutionary idea of this theory is the idea of diversity. Gardner claimed that we have seven intelligences functioning independently. This new idea was against the traditional understanding of intelligences, which was focusing on one or two capacities. In order for any capacity to be labeled as intelligence, Gardner set clear and specific criteria. The criteria have different roots as follow: (Gardner ,1999).

a. biological root:

1. Potential isolation by brain damage.

2.An evolutionary history and an evolutionary plausibility.

b. logical root:

3. An identifiable core operation or set of operations. 
4. Susceptibility to encoding from a symbol system.

c. developmental psychology root:

5. A distinctive developmental history with a definite set of "end state" performances.

6. The existence of idiot, savants, prodigies and other exceptional people.

d. traditional psychological root:

7. Support of experimental and psychological tasks.

8.Support from psychometric findings.

\subsection{Statement of the Problem:}

If every learner understands his uniqueness in the classroom, he will increase his opportunities for learning and his ability in aligning his potentials to specific tasks. 'Multiple intelligences' is one aspect of a learner's uniqueness. Actually, MI theory assumes that if there are programs that demonstrate the skills of real life in the eight intelligences for individuals from an early age then the individuals will have clear and more reliable bases to select the future career. (Armstrong, 2009). The study will examine the differences in multiple intelligences of students at DU in term of gender, and college.

\subsection{Research Questions:}

1. What are the multiple intelligences profiles of each college?

2. What are the differences in the multiple intelligences profiles according to college variable?

3. What are the multiple intelligences profiles according to the gender?

4. What are the differences in the multiple intelligences profiles according to gender variable?

\subsection{Research Hypotheses}

From questions number two and number four, the following hypotheses emerged:

1. There are no statistically significant differences at $(\alpha=0.05)$ in multiple intelligences of the profiles of the students attributed to college variable.

2. There are no statistically significant differences at $(\alpha=0.05)$ in the multiple intelligences profiles attributed to gender variable.

\subsection{Significance of the Study:}

Currently, the theory of Multiple Intelligences is considered as an effective tool in determining the diversity of the learners all over the world. This study highlights the relationship between multiple intelligences profiles and field of specialization. This issue is very important for the higher education students and it could be crucial for the student before selecting the college or the field of specialization.

To the knowledge of the researcher, this is the first study explores the multiple intelligences profiles of the students in Dhofar provenance in Sultanate of Oman. It is hoped that this study represents an indicator for the students to know if they are accommodated in the right specialization or not.

Enlighten the students in the high school or first-year students about the theory of multiple intelligences will help the student to choose the appropriate college and the specialty which match his or her intelligences profile. If the multiple intelligences scale is administered at the end of the high school or in the first year of the university, then the students will be more aware of their capabilities, skills, and intelligences and hence the chance of completing the university will be very high and consequently, the drop-out rate will be descending.

\subsection{Study Limitations}

- A sample of males and females students in Dhofar University.

- The validity and reliability of the instrument that is used in the study.

1.6 Operational Definitions of Study’s Terminology: (Gardener, 1983, 1993, 1995, 1999)

Verbal-Linguistic Intelligence: refers to an individual's ability to display a facility with words and languages. They are typically good at reading, writing, and telling stories. They have the ability to explain, teach, and they can learn a foreign language very easily. Mathematical-Logical Intelligence: refers to an individual's who are naturally excel in mathematics, computer programming and other logical reasoning.

Musical Intelligence: refers to individuals who display greater sensitivity to sounds, rhythms, tones, and music. People with strong musical intelligence normally have a good pitch and are able to sing, play musical instruments, and compose music. 
Visual-Spatial Intelligence: refers to the ability to visualize and mentally manipulate objects. People with strong visual-spatial intelligence have a strong visual memory and are often artistically inclined. BodilyKinesthetic Intelligence: refers to the ability to enjoy acting or performing. People with strong bodily-kinestheticintelligence often learn best by physically doing something. Bodily-Kinesthetic Intelligence is measured by the test of multiple intelligences

Interpersonal Intelligence: The ability to communicate effectively and empathize easily with others. People with strong Interpersonal Intelligence are usually extroverts and are characterized by their sensitivity to others' moods, feeling, and motivation.

Intrapersonal Intelligence: the ability to have highly self- aware People with strong Interpersonal Intelligence can understand their own emotions, goals, and motivations. Naturalist Intelligence: refers to individuals who have greater sensitivity to nature. They are good at taming and interacting with animals.

\section{Theoretical Literature and Related Studies:}

\subsection{Multiple Intelligences:}

Since it was published in 1983, MI theory challenged the traditional perception of intelligence which was basically recognizing one or two types of intelligences. MI theory emphasizes and promotes the idea of diversity and highlights the several ways way of employing these intelligences to developing the society and its advancement. (Kallenbach, 2006; Gardner, 2011).

All of us have abilities. We are strong in some abilities and weak in others. To develop our abilities, it's very important to select the best mean or best tool. Multiple Intelligences theory (MI) defines the intelligence based on three components: (1) Intelligence is a set of skills that can be used to solve problems or overcome difficulties (2) Intelligence is considered if there is an achieving of a product valued by the culture (3) Intelligence is considered when reaching a creative solution leads to new knowledge. (Gardner ,1983).

Armstrong (2009) displayed in details the intelligences of MI theory in his book "Multiple Intelligences in The Classroom". Armstrong highlighted some important point regarding the theory. These points are: (1) MI theory suggests that there are many intelligences, not just one intelligence. Each one of us possess the eight intelligences and they work together in an amazing and unique way (2) With encouragement, training, and appropriate program, most people can develop any intelligence to a good level of competency (3) All intelligences are functioning together in a complicated way (4) No standard features exist for anyone to be smart or intelligent in any field. Some people don't have the ability to read or write, but he is a great poet or a famous orator.

\subsection{Previous related studies:}

Kandeel (2016) conducted a study to find out the patterns of multiple intelligences of students and how it is related to the academic achievement in Mathematics course at King Saud. The results ranked the multiple intelligences of the study sample as: self, social, bodily, logical, verbal, visual, musical and natural intelligence.

Fardad, Koosha, and Shafiee (2015) explored the relationship between (MI) scores of EFL students according to their gender, and their vocabulary knowledge. The sample of the study consisted of 88 students (24 males and 64 females) from Khorasgan Azad University. The results show that there is no significant relation between MI scores and their vocabulary knowledge. Also the study revealed that no significant difference between males and females concerning different types of intelligences

Mustafa, Abu Jado, and Onoz (2014) conducted a research to explore the multiple intelligences type of Jordanian students at Yarmouk University. The researchers used the Multiple Intelligences Test (MIT) prepared by Onoz (2009). (759) students from Yarmouk University participated in the study. The results revealed that the linguistic intelligence came first, while the spatial intelligence came last.

Al-Faoury, Khataybeh, and Al-Sheikh (2011) studied the intelligences types of the Jordanian students in different public and private universities. To collect data, the researchers used a survey which was administered to (1436) students. The results showed that females excelled in linguistic and interpersonal intelligence. Also, the results showed that there were significant differences in the logical intelligences in favor of the governmental universities. Regarding the average factor, the study didn't find any significant differences in the multiple intelligences could be attributed to the average. 
Al-Aslani (2010) conducted a study to explore the impact of using a remedial strategy based on MI theory on improving the achievement in the geometry of slow learners. Attitudes towards geometry also have been investigated. The results showed that the remedial strategy has a positive effect and the performance of the experimental group is better than the performance of control group.

Ahmad (2010) explored the impact of a program designed according to MI theory on improving the academic achievement and developing the creative thinking of students in secondary commercial school. The number of participants was (120) female students. The sample was divided into (40) students represented the control group, and (80) students represented the experimental group. The results showed that the program has a positive effect and the performance of the experimental group is better than the performance of control group.

Alumran (2006) explored the multiple intelligences of the students at University of Bahrain and investigated the difference in multiple intelligences with respect to gender and the field of specialization. The researcher developed a multiple intelligences test to find out the intelligences profiles. The participants were (238) students from (13) different specializations. Using MANOVA, results found that dominant intelligences were social intelligence and Personal intelligence.

\section{Methodology}

\subsection{The study sample}

The sample of this study are students from four colleges at Dhofar University (DU). The students were selected randomly from different colleges. The total number of the student is 320 . The population of this study composed of (113) students from CAAS, (65) students from CCBA, (89) students from CE, and (53) students from CL. Table (1) and table (2) shows the distribution of the study sample according to college variable and gender variable:

Table 1: Distribution of sample in terms of college

\begin{tabular}{|l|l|l|l|}
\hline & Category & Number & Percent \% \\
\hline \multirow{5}{*}{ College } & College of Arts and Applied Sciences (CAAS) & 113 & 35.3 \\
\cline { 2 - 4 } & College of Commerce and Business Administration (CCBA) & 65 & 20.3 \\
\cline { 2 - 4 } & College of Engineering (CE) & 89 & 27.8 \\
\cline { 2 - 4 } & College of Law (CL) & 53 & 16.6 \\
\cline { 2 - 4 } & Total & 320 & 100.0 \\
\hline
\end{tabular}

Table 2: Distribution of sample in terms of gender

\begin{tabular}{|l|l|l|}
\hline Gender & Frequency & Percent \\
\hline Males & 141 & 44.1 \\
\hline Females & 179 & 55.9 \\
\hline Total & 320 & 100.0 \\
\hline
\end{tabular}

\subsection{Study Instruments and test scoring: Multiple Intelligences Scale}

After reviewing the literature and studying some inventories related to MI theory, the researchers developed a scale to measure the MI profile of the students. the scale developed mainly by taking advantage from Mackenzie (1999), Armstrong (2009) and Abdulkarim \& Al Jadiry (2012). Five Likert scale have been used: always apply, apply, apply sometimes, do not apply, and never apply. The maximum weight is (5) and it is given to the response always apply while the minimum is given (1) to the response never apply. The MI scale is written in both languages English and Arabic.

\subsection{Tool validity}

To confirm the validity, the scale has examined first by seven professors (The specializations of professors are: Psychology, Measurement and Evaluation, Curricula and instruction) The comments and suggestions of the referees have been studied and the final version of the scale has developed in both languages: Arabic and English then sent to English language teacher and Arabic language teacher for final revision.

\subsection{Tool Reliability:}

Regarding the reliability, the researchers applied the scale on an exploratory sample of 23 students. The reliability coefficient is calculated by using Cronbach Alpha and found to equal 0.89. 


\subsection{Study Procedures:}

The following procedure was implemented:

1. Preparing the MI scale after reviewing the theoretical literature

2. Getting the consents from the research department to conduct the study.

3. calculating validity and reliability of the scale.

4. Selecting the sample from undergraduate students at Dhofar University.

5. administering the scale on the study sample.

7. The statistical analyzing processing.

\subsection{Study Variables:}

1. Independent variables:

1) Gender (Males, females)

2) College ( CAAS, CCBA, CE, CL)

2. Dependent variable: The intelligences of students

\subsection{Data Analysis:}

(SPSS) program has been used to calculate the means and standard deviation. M ANOVA Test was also used to find out if the differences in multiple intelligences profiles were significant or not.

\section{Results and discussion:}

\section{1: Findings and discussions of the first question:}

The first question was: What are the multiple intelligences profiles of each college? Table (3) shows means, standard deviation, and the rank of the sample while figure (1) shows a column chart of the results.

Table (3): multiple intelligences profiles of DU students according to colleges

\begin{tabular}{llllllllll} 
College & & Linguistic & Logical & Spatial & Kinesthetic & Musical & Interpersonal & Intrapersonal & Naturalist \\
\hline CAAS & Mean & 28.7257 & 27.2832 & 26.9823 & 28.0000 & 25.0619 & 28.0619 & 30.9558 & 25.9469 \\
\cline { 2 - 9 } N=113 & Rank & $2^{\text {nd }}$ & $5^{\text {th }}$ & $6^{\text {th }}$ & $4^{\text {th }}$ & $8^{\text {th }}$ & $3^{\text {rd }}$ & $1^{\text {st }}$ & $7^{\text {th }}$ \\
\cline { 2 - 9 } & STDEV & 4.69849 & 4.93795 & 4.71317 & 4.24054 & 5.43843 & 4.49461 & 4.06727 & 4.72047 \\
\hline CCBA & Mean & 28.1385 & 27.0615 & 26.1231 & 27.0769 & 23.0462 & 28.8923 & 30.4462 & 25.6154 \\
\cline { 2 - 9 } N=65 & Rank & $3^{\text {rd }}$ & $5^{\text {th }}$ & $6^{\text {th }}$ & $4^{\text {th }}$ & $8^{\text {th }}$ & $2^{\text {nd }}$ & $1^{\text {st }}$ & $7^{\text {th }}$ \\
\cline { 2 - 9 } & STDEV & 4.35487 & 4.52382 & 5.17357 & 4.53909 & 6.85208 & 4.94066 & 4.55532 & 6.00441 \\
\hline CE & Mean & 27.8989 & 28.6854 & 28.3146 & 29.4719 & 25.3596 & 27.5281 & 30.7640 & 27.7978 \\
\cline { 2 - 9 } N=89 & Rank & $5^{\text {th }}$ & $3^{\text {rd }}$ & $4^{\text {th }}$ & $2^{\text {nd }}$ & $8^{\text {th }}$ & $7^{\text {th }}$ & $1^{\text {st }}$ & $6^{\text {th }}$ \\
\cline { 2 - 9 } & STDEV & 4.07332 & 5.21492 & 5.16455 & 4.56541 & 5.00283 & 4.79604 & 4.43135 & 4.73185 \\
\hline LAW & Mean & 29.5472 & 28.0189 & 26.2642 & 27.6792 & 22.6981 & 27.6604 & 31.1887 & 27.1698 \\
\cline { 2 - 9 } N=53 & Rank & $2^{\text {nd }}$ & $3^{\text {rd }}$ & $7^{\text {th }}$ & $4^{\text {th }}$ & $8^{\text {th }}$ & $5^{\text {th }}$ & $1^{\text {st }}$ & $6^{\text {th }}$ \\
\cline { 2 - 9 } & STDEV & 3.71362 & 4.72510 & 5.05794 & 4.66894 & 6.21594 & 4.96504 & 4.02901 & 4.58566
\end{tabular}

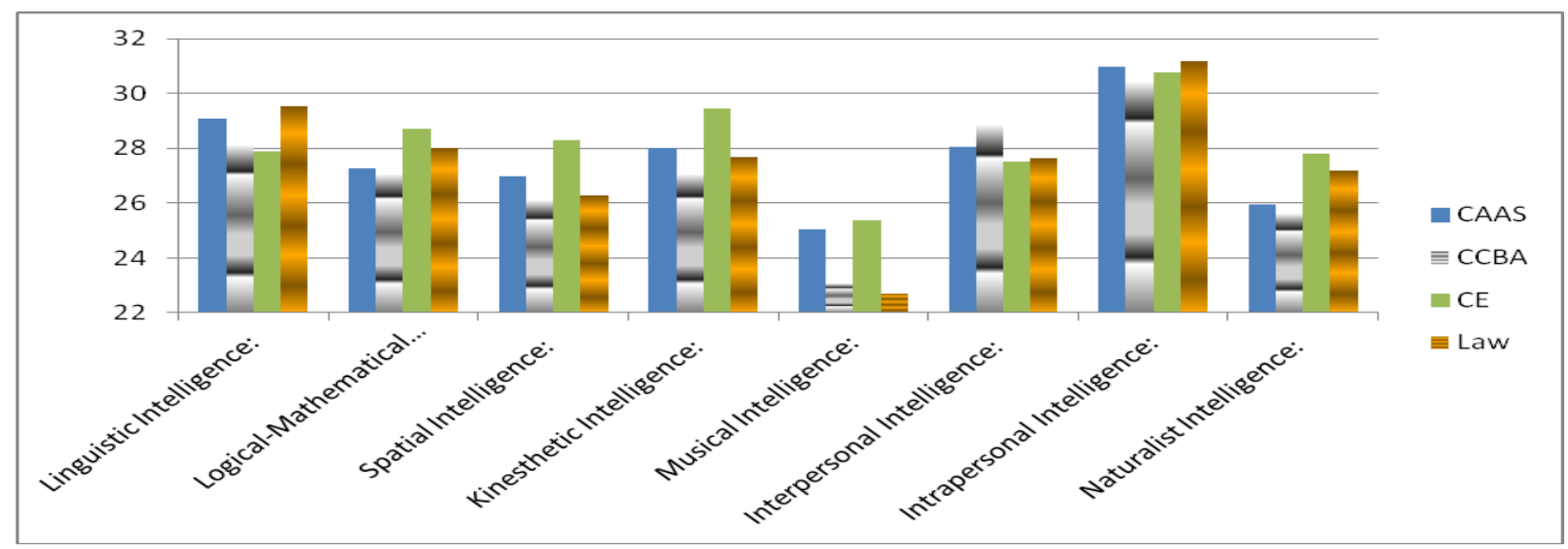

Figure (1): a column chart of the four colleges results. 
Table (3) reveals an interesting result. In all colleges, the intrapersonal intelligence ranks the first and the musical intelligences ranks the last. Linguistic intelligence occupies the fifth rank in CE, third rank in CCBA, and the second rank in both CAAS and Law college.

Logical-mathematical intelligence has a strange distribution. In CE and Law college the Logical-mathematical intelligences comes in the third rank, which is good for engineering and law students. But in CAAS and CCBA students the Logical-mathematical intelligence fells down to the fifth rank. taking into account there are two scientific specializations in CAAS (Computer \& Mathematics) and one scientific specialization in CCBA (Accounting and finance).

Regarding spatial intelligence, it ranks the fourth in CE, sixth in both CAAS and CCBA and seventh in Law College. For Kinesthetic intelligence, CE occupies the second rank while other colleges rank the fourth. Taking into consideration that on DU level this intelligence ranks the third. The biggest variation in the rank of intelligence takes place in the interpersonal intelligence. CCBA ranks the second, CAAS ranks the third, Law ranks the fifth, CE ranks the seventh.

Finally, the Naturalist intelligence is stabilizing in the sixth rank as in CE and Law students or in the seventh rank as in CAAS and CCBA students.

The result of having the intrapersonal intelligence in the first rank can be attributed to the fact that the sample of the study belongs to the late adolescence stage. Based on the theory of Developmental Psychology of Erikson (1959), the sample of the study lies between stage number (5): Adolescence stage and stage number (6): Young Adult. During stage (5), adolescents major concern is finding their selves and determining their personal identity. They tried to explore the personal values and they start the first trial to set their future goals. In this period, they begin to construct their identity. In stage (6) the people begin to share their self-more intimately with others. They explore relationships leading toward longer-term commitments with someone other than a family member (McLeod,2017).

The musical intelligence ranks last and this can be attributed to the fact that university environment is highly dominated by academic activities which are full of reports, seminars, projects, and exams. While the other activities such as musical events are just conducted on specific occasions such as the National day or graduation ceremony. There are no students' clubs for music or students' bands. Moreover, the Dhofar community is a conservative community consists of Tribes and clans which usually doesn't encourage or support Concerts or musical shows.

The results of the current study are in harmony with the results of the studies of Al- Faouri, Khataybeh, \& AlSheikh (2011) and Kandeel (2016) were in all studies the intrapersonal intelligence ranks first and interpersonal intelligence ranks second. The same results have been displayed in Alumran (2006), where the top three intelligence were interpersonal, intrapersonal, linguistic which is the exactly consistent with the result of this study. This study also is partially consistent with the result of the study of Mustafa, Abu Jado, \& Onoz (2014). In both studies, the interpersonal intelligence ranks second but the intrapersonal and linguistic intelligence exchanged the first and third position.

Regarding the musical intelligence, the students of this study give themselves the lowest score which also is in a full agreement with Al- Faouri, Khataybeh, \& Al-Sheikh (2011) where the musical intelligence ranks the last. In Alumran (2006), the musical intelligence ranks seventh out of nine intelligences while in Alumran (2006) study the existential intelligence has been also considered. In the study of Mustafa, Abu Jado, \& Onoz (2014), the musical intelligence ranks forth which represents a clear difference from other studies.

\section{2: Findings and discussions of the second question:}

The second question was: What are the differences in the multiple intelligences profiles according to college variable? From this question, the following hypothesis emerged:

There are no statistically significant differences at $(\alpha=0.05)$ in multiple intelligences of the profiles of the students attributed to college variable.

One-way MANOVA tests of the differences between the means of sample score on the eight intelligences has been administered to find out if there are statistically significant differences in each intelligence according to college variable. Table (4) shows the results: 
Table (4): Multivariate Tests according to college variable

\begin{tabular}{|l|l|l|l|l|l|l|l|}
\hline Effect & Value & F & Hypothesis df & Error df & Sig. & Partial Eta Squared \\
\hline College & Wilks' Lambda & .813 & 2.759 & 24.000 & 896.795 & .000 & .067 \\
\hline
\end{tabular}

Table (3) shows that there is a statistically significant difference in intelligences based on gender, $F(24,897)=$ 2.759, $p=0.000$; Wilk's $\Lambda=0.813$, partial $\eta 2=0$. .067. To determine how the intelligence variable differs for the college variable, we need to look at the Tests of Between-Subjects Effects shown in Table (4):Tests of (BetweenSubjects Effects) confirms the same result. table (5) shows the details

Table (4): Tests of Between-Subjects Effects

\begin{tabular}{|l|l|l|l|l|l|l|l|}
\hline $\begin{array}{l}\text { Source of } \begin{array}{l}\text { Variance } \\
\text { Vependent }\end{array} \\
\text { Variable }\end{array}$ & $\begin{array}{l}\text { Sum of } \\
\text { Squares }\end{array}$ & $\begin{array}{l}\text { Degrees of } \\
\text { Freedom }\end{array}$ & $\begin{array}{l}\text { Means of } \\
\text { Squares }\end{array}$ & $\begin{array}{l}\text { F } \\
\text { Value }\end{array}$ & $\begin{array}{l}\text { Statistical } \\
\text { Significant }\end{array}$ & $\begin{array}{l}\text { Partial } \\
\text { Eta } \\
\text { Squared }\end{array}$ \\
\hline \multirow{4}{*}{ College } & Linguistic & 130.691 & 3 & 43.564 & 1.862 & .136 & .017 \\
\cline { 2 - 8 } & Logical & 137.136 & 3 & 45.712 & 1.902 & .129 & .018 \\
\cline { 2 - 8 } & Spatial & 231.399 & 3 & 77.133 & 3.094 & .027 & .029 \\
\cline { 2 - 8 } & Kinesthetic & 244.545 & 3 & 81.515 & 4.088 & .007 & .037 \\
\cline { 2 - 8 } & Musical & 403.095 & 3 & 134.365 & 4.033 & .008 & .037 \\
\cline { 2 - 8 } & Interpersonal & 78.043 & 3 & 26.014 & 1.153 & .328 & .011 \\
\cline { 2 - 8 } & Intrapersonal & 18.552 & 3 & 6.184 & .340 & .797 & .003 \\
\cline { 2 - 8 } & Naturalist & 256.100 & 3 & 85.367 & 3.429 & .017 & .032 \\
\hline
\end{tabular}

Error $=316$

From table (4) we see that four intelligences have a statistically significant effect on college variable. Spatial intelligence has a statistically significant effect on college variable $\left(F(3,316)=3.094 ; p<0.05\right.$; partial $\eta^{2}=$ $.029)$, Kinesthetic intelligence has a statistically significant effect on college variable $(F(3,316)=4.088 ; p<$ 0.05 ; partial $\left.\eta^{2}=.037\right)$, Musical intelligence has a statistically significant effect on college variable $(F(3,316)=$ 4.033; $\mathrm{p}<0.05$; partial $\eta 2=.037)$, and Naturalist intelligence has a statistically significant effect on college variable $(\mathrm{F}(3,316)=3.429 ; \mathrm{p}<0.05 ;$ partial $\eta 2=.032)$.

To determine which of the means for the four (4) colleges are significantly different from the others in the four (4) intelligences above, Post Hoc Analysis (Tukey) has been administered. Table (5) shows the results for the intelligences that have a statistically significant effect on college variable (Spatial, Kinesthetic, Musical, and Naturalist).

Table (5): Post Hoc Analysis (Tukey)

\begin{tabular}{|c|c|c|c|c|c|}
\hline $\begin{array}{l}\text { Dependent } \\
\text { Variable }\end{array}$ & (I) Colleges & (J) Colleges & Mean Difference (I-J) & Std. Error & Sig. \\
\hline \multirow[t]{3}{*}{ Spatial } & \multirow[t]{3}{*}{ Engineering } & CAAS & 1.3323 & .70765 & .238 \\
\hline & & CCBA & $2.1915 *$ & .81468 & $.038^{*}$ \\
\hline & & Law & 2.0505 & .86634 & .086 \\
\hline \multirow[t]{3}{*}{ Kinesthetic } & \multirow[t]{3}{*}{ Engineering } & CAAS & 1.4719 & .63282 & .094 \\
\hline & & CCBA & $2.3950 *$ & .72853 & $.006^{*}$ \\
\hline & & Law & 1.7927 & .77473 & .097 \\
\hline \multirow[t]{3}{*}{ Musical } & \multirow[t]{3}{*}{ Engineering } & CAAS & .2976 & .81808 & .984 \\
\hline & & CCBA & 2.3134 & .94180 & .069 \\
\hline & & Law & $2.6614^{*}$ & 1.00153 & $.041^{*}$ \\
\hline \multirow[t]{3}{*}{ Naturalist } & \multirow[t]{3}{*}{ Engineering } & CAAS & $1.8509 *$ & .70713 & $.046^{*}$ \\
\hline & & CCBA & $2.1824^{*}$ & .81408 & $.039^{*}$ \\
\hline & & Law & .6279 & .86570 & .887 \\
\hline
\end{tabular}

Table (5) shows the superiority of Engineering students in the four intelligence. For Spatial intelligence, there is a statistically significant differences at $(\alpha=0.05)$ between the average of Engineering students and CCBA students for the benefit of Engineering students. Regarding Kinesthetic intelligence, there is a statistically significant differences at $(\alpha=0.05)$ between the average of Engineering students and CCBA students for the benefit of Engineering students. 
Regarding Musical intelligence, there is a statistically significant differences at $(\alpha=0.05)$ between the average of Engineering students and Law students for the benefit of Engineering students. Regarding Naturalist intelligence, there is a statistically significant differences at $(\alpha=0.05)$ between the average of Engineering students and all of CAAS students and CCBA students for the benefit of Engineering students.

\section{3: Findings and discussions of the third question:}

The third question was: What are the multiple intelligences profiles according to the gender? Table (6) shows means, standard deviation, and the rank of the sample while figure (2) shows a column chart of the results.

Table (6): multiple intelligences profiles of DU students according to gender

\begin{tabular}{lllllll} 
Type of Intelligence & \multicolumn{7}{c}{ Males } & \multicolumn{7}{l}{ Females } \\
\cline { 2 - 7 } & Mean & STDEV & Rank & Mean & STDEV & Rank \\
\hline Linguistic & 28.2979 & 4.09834 & $2^{\text {nd }}$ & 28.6816 & 4.50022 & $2^{\text {nd }}$ \\
\hline Logical & 28.1348 & 5.03732 & $3^{\text {rd }}$ & 27.4469 & 4.82401 & $6^{\text {th }}$ \\
\hline Spatial & 26.3972 & 5.35174 & $7^{\text {th }}$ & 27.581 & 4.73427 & $5^{\text {th }}$ \\
\hline Kinesthetic & 27.8582 & 4.19112 & $4^{\text {th }}$ & 28.4134 & 4.7767 & $3^{\text {rd }}$ \\
\hline Musical & 23.6596 & 5.91467 & $8^{\text {th }}$ & 24.8827 & 5.76532 & $8^{\text {th }}$ \\
\hline Interpersonal & 27.539 & 4.75472 & $5^{\text {th }}$ & 28.3911 & 4.73252 & $4^{\text {th }}$ \\
\hline Intrapersonal & 30.1631 & 4.11205 & $1^{\text {st }}$ & 31.3687 & 4.29898 & $1^{\text {st }}$ \\
\hline Naturalist & 27.1489 & 5.16158 & $6^{\text {th }}$ & 26.162 & 4.92432 & $7^{\text {th }}$
\end{tabular}

Table (6) shows that the distribution of the intelligence of the males' sample is ranked as follows: Intrapersonal, Linguistic, Logical, Kinesthetic, Interpersonal, Naturalist, and finally the Musical intelligence. Regarding the females sample, the rank was as follows: Intrapersonal, Linguistic, Kinesthetic, Interpersonal, Spatial, Logical, Naturalist, and finally the Musical intelligence.

Table (6) shows that females estimated their intelligences higher than males in all intelligences except in mathematical and Naturalist intelligence. Szymanowicz \& Furnham (2013), reported that the results of many researches conducted all over the world indicated that males consistently tend to estimate their intelligence, especially mathematical intelligences higher than females.

In general, the most familiar intelligences for both males and females were Intrapersonal and Linguistic. The Logical intelligence was more favorable in the male sample while the Spatial intelligence was more favorable in the female sample. Finding out if the differences in the mean between males and females are significant or not, will be conducted later when discussing question number (4).

4.4: Findings and discussions of the fourth question:

The fourth question was: What are the differences in the multiple intelligences profiles of DU students according to gender? From this question, the following hypothesis emerged: There are no statistically significant differences at $(\alpha=0.05)$ in the multiple intelligences profiles of the DU students attributed to the gender variable.

One-way MANOVA tests of the differences between the means of sample score on the eight intelligences has been administered to find out if there are statistically significant differences in each intelligence according to gender variable. Table (7) shows the results:

Table (7): Multivariate Tests

\begin{tabular}{|l|l|l|l|l|l|l|l|}
\hline Effect & Value & F & $\begin{array}{l}\text { Hypothesis } \\
\text { df }\end{array}$ & Error df & Sig. & $\begin{array}{l}\text { Partial Eta } \\
\text { Squared }\end{array}$ \\
\hline gender & Wilks' Lambda & .901 & 4.287 & 8.000 & 311.000 & .000 & .099 \\
\hline
\end{tabular}

Table (7) shows that there is a statistically significant difference in intelligences based on gender, $F(8,311)=$ 4.284, $p<.0005$; Wilk's $\Lambda=0.901$, partial $\eta^{2}=0.099$. To determine how the intelligence variable differs for the gender variable, we need to look at the Tests of Between-Subjects Effects shown in Table (8): 
Table (8): Tests of Between-Subjects Effects

\begin{tabular}{|l|l|l|l|l|l|l|l|}
\hline $\begin{array}{l}\text { Source } \\
\text { Variance }\end{array}$ & $\begin{array}{l}\text { Dependent } \\
\text { Variable }\end{array}$ & $\begin{array}{l}\text { Sum of } \\
\text { Squares }\end{array}$ & $\begin{array}{l}\text { Degrees of } \\
\text { Freedom }\end{array}$ & $\begin{array}{l}\text { Means of } \\
\text { Squares }\end{array}$ & $\begin{array}{l}\text { F } \\
\text { Value }\end{array}$ & $\begin{array}{l}\text { Statistical } \\
\text { Significant }\end{array}$ & $\begin{array}{l}\text { Partial Eta } \\
\text { Squared }\end{array}$ \\
\hline \multirow{5}{*}{ Gender } & Linguistic & 29.075 & 1 & 29.075 & 1.234 & .267 & .004 \\
\cline { 2 - 9 } & Logical & 37.314 & 1 & 37.314 & 1.542 & .215 & .005 \\
\cline { 2 - 9 } & Spatial & 110.538 & 1 & 110.538 & 4.394 & .037 & .014 \\
\cline { 2 - 8 } & Kinesthetic & 24.317 & 1 & 24.317 & 1.186 & .277 & .004 \\
\cline { 2 - 8 } & Musical & 117.992 & 1 & 117.992 & 3.470 & .063 & .011 \\
\cline { 2 - 8 } & Interpersonal & 57.261 & 1 & 57.261 & 2.546 & .112 & .008 \\
\cline { 2 - 8 } & Intrapersonal & 114.637 & 1 & 114.637 & 6.444 & .012 & .020 \\
\cline { 2 - 8 } & Naturalist & 76.823 & 1 & 76.823 & 3.036 & .082 & .009 \\
\hline
\end{tabular}

Error $\mathrm{df}=318$

We can see from table (8) that spatial intelligence has a statistically significant effect on gender $(F(1,318)=$ 4.394; $p<.05$; partial $\eta 2=.014)$. Also intrapersonal intelligence has a statistically significant effect on gender $(F(1,318)=6.444 ; p<.05 ;$ partial $\eta 2=.020)$

The table above shows that there are statistically significant differences only in Spatial intelligence and Intrapersonal intelligence. While there are no statistically significant differences on the rest of the intelligences. Table (6) shows that the statistically significant differences on Spatial intelligence and Intrapersonal intelligence are both in favor of females. This result is partially in agreement with the result of Al- Faouri, Khataybeh, \& AlSheikh (2011) study and Loori (2005) study especially in intrapersonal intelligence, which is in favor of females in all mentioned studies. At the same time the result of the study is in disagreement with the studies of Furnham \& Ward, 2001: Furnham, Tang, Lester, O'Connor, \& Montgomery, (2002); Weiss, Kemmler, Deisenhammer, Fleischhacker, \& Delazer, (2003) which explain that there are statistically significant differences between males and females in all intelligences in favor of males. Also, it is in disagreement with Farunham \&Akande (2004) which shows that the females perform better than males in all intelligences.

\section{Conclusions and Recommendations:}

The result of the study shows that intrapersonal intelligence has the highest score and ranks first always while musical ranks last. For males, intelligences have the following order: intrapersonal, Linguistic, Logical, Kinesthetic, Interpersonal, Naturalist, Spatial, and Musical intelligences respectively. For females, intelligences have the following order: intrapersonal, Linguistic, Kinesthetic, Interpersonal, Spatial, Logical, Naturalist, and Musical intelligences respectively. The MANOVA test shows that there are statistically significant differences only in Spatial intelligence and Intrapersonal intelligence in favor of females for both intelligences. Regarding college variable, the study finds that there are statistically significant differences in four intelligences: Spatial, Kinesthetic, Musical, and Naturalist intelligences. The MANOVA test highlights the superiority of Engineering students in the four intelligence. In the light of the results of this study the researchers recommend the following:

1. Universities are invited to make some changes in their syllabi and teaching methods they used in the classroom to suit the dominant multiple intelligences of the students.

2. Students and advisors are recommended to take into account the profile of multiple intelligence before selecting the college.

\section{References}

Abdulkarim, R., Al Jadiry, A. (2012). The Effect of Cooperative Learning Group Division Based onMultiple Intelligences Theory and Previous Achievement on Scientific Thinking Skills Development of Ninth Grade Students in Oman. European Journal of Social Sciences, Vol. 27(4), 553-569.

Ahmad, M. A. (2010). The impact of a program based on multiple intelligences in developing creative thinking and achievement among students of the commercial secondary school. Unpublished M.A thesis, The Institute of Educational Studies, University of Cairo, Egypt.

Al-Aslani, R. M. (2010). The effectiveness of a remedial strategy in light of multiple intelligences on developing geometry achievement and attitudes towards geometry among 2nd preparatory slow learners in Jeddahgovernorate. Unpublished Ph. D thesis, Females Faculty of Education, Jeddah, Saudi Arabia. 
Al-Faoury, O., Khataybeh, A. \& Al-Sheikh, K. (2011). Multiple Intelligences Of Students At Jordanian Universities. Journal of International Education Research, Vol. 7 (4), 83-94.

Alumran, j. (2006). Multiple Intelligences for Bahraini Students at the University Level According to Gender and Academic Specializations: Is the Right Student in the Right Specialization? Journal of Educational and Psychological Sciences. University of Bahrain. Vol. 7(3). 13-43.

Armstrong, T. (2009). Multiple Intelligences in the Classroom (3rd ed.). Alexandria: ASCD.

Gardner, H. (1983). Frames of Mind: The Theory of Multiple Intelligences. New York: Basic Books

Gardner, H. (1993). Multiple Intelligences: The Theory in Practice. New York: Basic Books.

Gardner, H (1995). Reflections on multiple intelligences: Myths and messages. Phi Delta Kappan, 77(3), $200-210$. Gardner, H. (1999). Intelligence Reframed: Multiple Intelligences for the 21 st Century. New York: Basic Books.

Gardner, H. (2011). Frames of Mind: Multiple Intelligences. (3rd Ed.). New York: Basic Books.

Fardad, Z, Koosha, M., \& Shafiee, S. (2015). Relationship between EFL Learners' Multiple Intelligence Scores, Gender, and Their Vocabulary Knowledge. Research Journal of Recent Sciences Vol. 4(12), 29-36.

Furnham, A., \& Akande, A. (2004). African parents' estimates of their own and their children's multiple intelligence. Current Psychology: Developmental, Learning, Personality, Social, 22(4).281-294.

Furnham, A. \& Ward, W. (2001). Sex differences, test experience, and the self-estimation of multiple intelligences. New Zealand Journal of Psychology, 30,52-59.

Furnham, A., Tang, T., Lester, D., O’Connor, R., \& Montgomery, R. (2002). Self-estimates of ten multiple intelligences. Sex and National differences and the perception of famous people. European Psychologist, 7, 245-255. https://doi.org/10.1027//1016-9040.7.4.245

Kallenbach, S. (2006). Emerging themes in adult multiple intelligences research. Focus on Basics, 3, (A), 16-20.

Kandeel, R. (2016). Multiple Intelligences Patterns among Students at King Saud University and Its Relationship with Mathematics' Achievement. Journal of Education and Learning, Vol. 5(3), 94-106. https://doi.org/10.5539/jel.v5n3p94.

Loori, A.( 2005). Multiple Intelligences: A comparative study between the preferences of males and females. Social Behavior and Personality, 33(1), 77-88. https://doi.org/10.2224/sbp.2005.33.1.77

McLeod, S. (2017). Erik Erikson. Retrieved from: https://www.simplypsychology.org/Erik-Erikson.html

McKenzie, W. (1999). Multiple Intelligences Survey Retrieved from http://surfaquarium.com/MI/ Mlinvent.htm.

Mustafa, S., Abu Jado, S. and Onoz, S. (2014). Types of Multiple Intelligences among Undergraduate Students at Yarmouk University in Light of Gardner's Theory. International Journal of Humanities and Social Science, Vol. 4(6), 140-153.

Sternberg, R.J. (1990). Metaphors of mind: Conceptions of the nature of intelligence. Cambridge: New York: Cambridge University Press.

Szymanowicz, A., Furnham, A. (2013). Gender and Gender Role Differences in Self- and Other-Estimates of Multiple Intelligences. The Journal of Social Psychology. Vol. 153(4): 399-423. https://doi.org/10.1080/00224545.2012.754397.

Vygotsky, L. S. (1978). Mind in society: The development of higher psychological processes. (M. Cole, V. JohnSteiner, S. Scribner, \& E. Souberman, Eds.). Cambridge, Massachusetts: Harvard University Press.

Weiss, E.M., Kemmler, G., Deisenhammer, E.A., Fleischhacker,W. \& Delazer, M. (2003). Sex differences in cognitive functions. Personality and Individual Differences, 35 (4), 863-875. https://doi.org/10.1016/S0191-8869(02)00288-X.

Wechsler, D. (1944). The measurement of adult intelligence (3rd ed.). Baltimore: Williams \& Wilkins. https://doi.org/10.1037/11329-000. 